\title{
Research on performance evaluation method of effective assets of power grid based on value engineering
}

\author{
Wang Mianbin ${ }^{1}$, Niu Xiaoxuan ${ }^{2}, A n \operatorname{Lei}^{1}$, Li Jinchao ${ }^{2,3 *}$ \\ ${ }^{1}$ State Power Economic Research Institute China State Grid Jibei Electric Power Company Limited, Beijing 102209, China \\ ${ }^{2}$ School of Economics and Management, North China Electric Power University, Beijing, 102206, China \\ ${ }^{3}$ Beijing Key Laboratory of New Energy and Low-Carbon Development, North China Electric Power University, Beijing, 102206, China
}

\begin{abstract}
The effective asset of power grid is an important basis for the development of power grid enterprises and government regulation. Based on the value and functional characteristics of power grid assets, this paper establishes an evaluation index system for effective asset function of power grids. The analytic hierarchy process and entropy weight method are used to calculate the subjective and objective weights of each functional index, and the subjective and objective weights are combined by the method of squared deviation. The combined weights of the indicators are combined with the value engineering evaluation model to calculate the effective asset value coefficient, which is taken as the effective asset performance value. Finally, the relevant data of a provincial power grid enterprise for 2014-2018 is used. The established model is validated and the calculation results show that the established optimal model is feasible.
\end{abstract}

\section{Introduction}

The effective asset of the grid is an important factor in determining the allowable income and transmission and distribution price of the grid enterprises under the permitted cost plus reasonable pricing. Therefore, it is of great practical significance to carry out research on the performance evaluation of effective assets of power grids.

$\mathrm{Xu}$ Jiantao (2016) studied the adoption of the $1+\mathrm{N}$ model in the implementation of agricultural network projects in the value engineering journals, and has significant effects on improving the quality of agricultural network projects and increasing the speed of effective asset formation [1]. In the context of the reform of the power system, Zhang Cun (2017) studied the significance of effective assets in promoting the reform of the power system and the reliable and efficient allocation of national energy resources [2]. In response to the research on the effective asset verification method under the new round of power system reform, Dong Heyun (2016) constructed a method for verifying the effective assets of transmission and distribution based on the Choquet integral investment effectiveness evaluation model, and effectively suppressed the generation of "AJ effect" [3]. Ye Ze (2017) proposed to develop an effective asset pricing method based on utilization efficiency and implementation rules and assessment criteria for effective asset supervision based on analyzing and summarizing the methods for determining effective assets of transmission and distribution networks in typical countries and regions[4]. Wu Fan (2017) combined the use characteristics of grid assets with asset management efficiency to establish an effective asset utilization efficiency accounting method, and approved the effective asset measurement base and transmission and distribution price permitted income based on the standard use rate [5].

Based on the reform of China's transmission and distribution price, we evaluate the value of effective assets of power grid enterprises by using value engineering methods. It is expected to enrich the effective asset evaluation system and provide a scientific reference for the management of effective assets of power grid enterprises, so that grid enterprises can develop better.

\section{Value engineering evaluation model based on combined weight}

Value Engineering (VE) is an emerging method of economic analysis. It is an organized activity to reliably realize the necessary functions of products with the lowest total cost, so as to obtain the best comprehensive benefits. Value engineering consists of three basic elements, namely, value, function and cost. The meaning of "value" in value engineering is the ratio of the function of the product to the total cost of the product, ie

$$
V=\sum_{i=1}^{n} F_{i} \times w_{i} / \mathrm{C}
$$

Where $V$ is the value; $F_{i}$ is the $i$-th functional indicator, $w_{i}$ is the weight of the $i$-th functional indicator, and $\mathrm{C}$ is the cost. The rationality of the weight of the functional indicators in the above formula is one of the keys to the credibility of the value calculation results. 
Aiming at the problem of effective assets performance evaluation of power grid enterprises, we use an evaluation model based on value engineering, which combines Analytic Hierarchy Process (AHP) and Entropy. Based on the construction of effective asset function index system of power grid, AHP is firstly applied to rationalize and stratify the effective asset function of power grid, establish hierarchical structure model, and calculate the objective weight of functional index. Then Entropy is applied to calculate the effective asset function index of the power grid based on objective information to obtain the subjective weight. Finally, the combined weight which embodies subjective and objective weight combined idea is calculated by the method of deviation sum of squares. The process of value engineering evaluation model based on combined weights is shown in Figure 1.

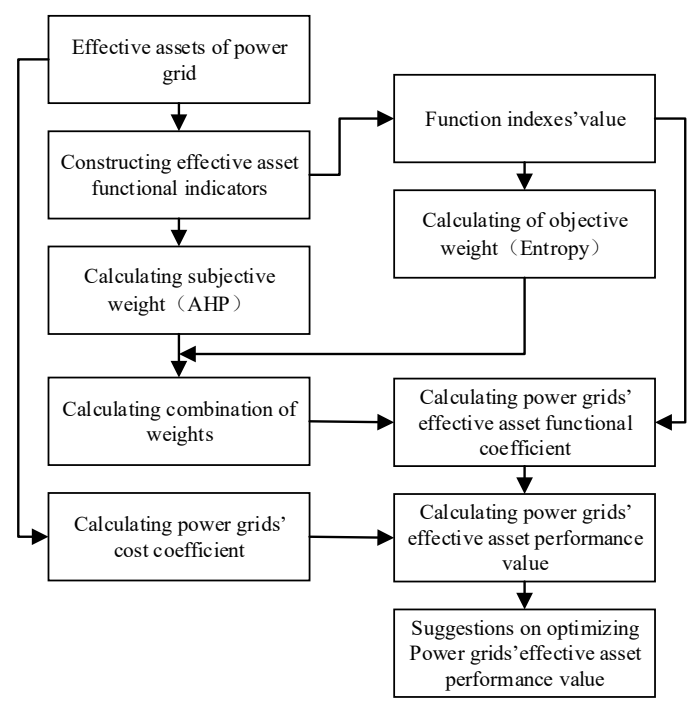

Fig.1. Flow chart of measurement of effective assets performance of power grid

Among them, the value coefficient is calculated as follows:

$$
V I_{j}=\frac{\sum_{i=1}^{n} F_{i j} \times w_{i} / \sum_{j=1}^{m}\left(\sum_{i=1}^{n} F_{i j} \times w_{i}\right)}{C_{j} / \sum_{j=1}^{m} C_{j}}
$$

Where, $V I_{j}$ represents the effective asset value coefficient (performance value) of power grid in year $j$, $F_{i j}$ represents the index value of function index $i$ in year $j, w_{i}$ represents the combination weight of function index $i, \sum_{j=1}^{m}\left(\sum_{i=1}^{n} F_{i j} \times w_{i}\right)$ represents the weighted sum of function value of $m$ years. $C_{j}$ represents the effective asset value in year $j$, and $\sum_{j=1}^{m} C_{j}$ represents the total effective assets of $m$ schemes.

\section{Grid effective asset function indicator construction}

To promote the development of power grid enterprises and evaluate the development performance of effective power grid assets, it is necessary to build a systematic and different performance evaluation index system, which can scientifically judge and evaluate the performance of effective power grid assets. Function refers to the various properties of the project to meet the purpose of use, including security, physics, economy and society. The grid effective asset function indicator system constructed is shown in Figure 2.

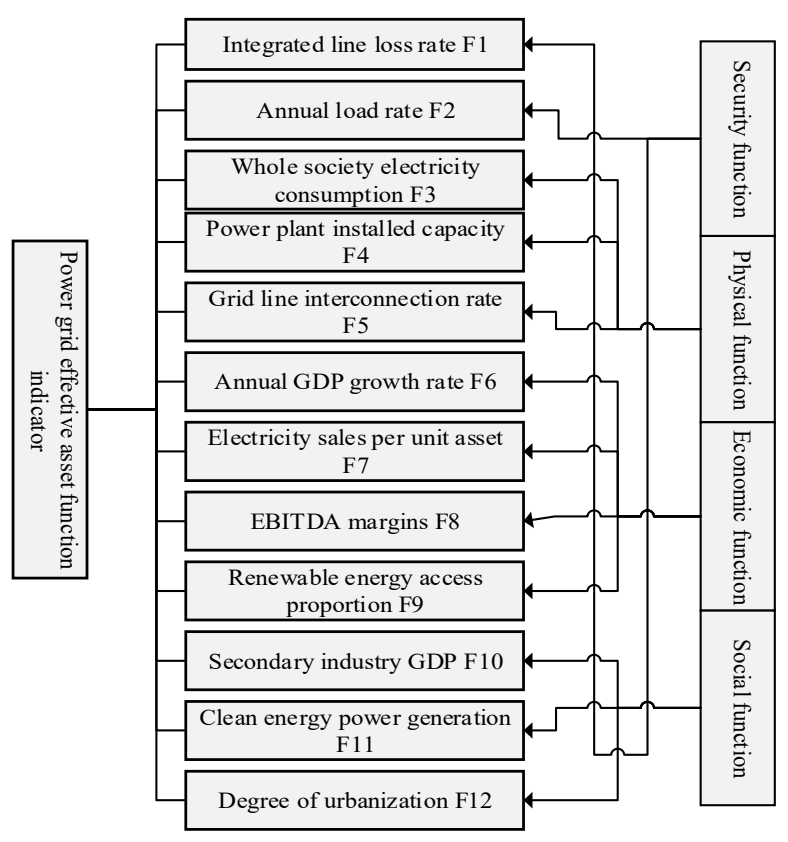

Fig.2. Grid effective asset function indicator system

\section{Empirical}

Under the mode of "permitted cost plus reasonable income" based on effective assets, the effective asset performance of power grid has a great impact on power grid economy, and the continuous enrichment of power grid functions also brings more external benefits. At the same time, it is understood that the rapid improvement of informatization level and economy of a certain provincial power grid are getting more and more attention, which has a great demand for improving power grid economy and accelerating the development of the company. Therefore, the effective asset performance of this provincial power grid is selected as a case study to use the above evaluation model.

For the five-year effective assets of a provincial power grid and the statistical value of its functional benefit output indicators, the values of the functional indicators obtained by the positive, negative and moderate standardization methods of quantitative indicators are shown in Table 1. 
Table 1. 5-year performance evaluation index value of a provincial power grid company

\begin{tabular}{c|c|c|c|c|c|c}
\hline & Grid year & 2014 & 2015 & 2016 & 2017 & 2018 \\
\hline \multirow{5}{*}{$\begin{array}{c}\text { Functional } \\
\text { indicator }\end{array}$} & Effective assets & 3353651 & 3712002 & 4234536 & 4251082 & 4528719 \\
\cline { 2 - 7 } & F1 & 0.96200 & 1.00000 & 0.97405 & 0.97406 & 0.92770 \\
\cline { 2 - 7 } & F3 & 0.99209 & 0.99812 & 1.00000 & 0.98991 & 0.98753 \\
\cline { 2 - 7 } & F4 F6 & 0.70943 & 0.78394 & 0.82296 & 0.91903 & 1.00000 \\
\cline { 2 - 7 } & F7 & 0.53144 & 0.92031 & 0.92282 & 0.86360 & 1.00000 \\
\cline { 2 - 7 } & F8 & 0.84483 & 0.88698 & 0.89898 & 0.90885 & 1.00000 \\
\cline { 2 - 7 } & F9 & 0.82832 & 0.87057 & 0.91410 & 0.94518 & 1.00000 \\
\cline { 2 - 7 } & F10 & 0.70985 & 0.77746 & 0.84984 & 0.92241 & 1.00000 \\
\cline { 2 - 7 } & F11 & 0.44948 & 0.51399 & 0.68439 & 0.87193 & 1.00000 \\
\hline
\end{tabular}

On the basis of obtaining the five-year performance evaluation function index value of a provincial power grid company, the subjective weighting method AHP and the objective weighting method Entropy are used to calculate the weight coefficients of each functional index respectively, and then the combined weights are calculated by the squared sum of dispersion method. The above calculations are completed by matlab software. The specific results are shown in Table 2

Table 2. Subjective Objective and Combination weights

\begin{tabular}{c|c|c|c}
\hline Functional indicator & AHP & Entropy & Combination weight \\
\hline F1 & 0.01212 & 0.0031 & 0.0046 \\
\hline F2 & 0.03636 & 0.0001 & 0.0062 \\
\hline F3 & 0.35945 & 0.0085 & 0.0707 \\
\hline F4 & 0.04898 & 0.0751 & 0.1978 \\
\hline F5 & 0.11609 & 0.2143 & 0.0163 \\
\hline F6 & 0.01754 & 0.0160 & 0.0575 \\
\hline F7 & 0.07564 & 0.0539 & 0.0422 \\
\hline F8 & 0.17589 & 0.0153 & 0.0274 \\
\hline F9 & 0.05473 & 0.0219 & 0.0739 \\
\hline F10 & 0.06640 & 0.0754 & 0.3820 \\
\hline F11 & 0.00761 & 0.4573 & 0.0542 \\
\hline
\end{tabular}

Formula (2) is used to calculate the value coefficient of effective assets of a provincial power grid in each year, as shown in Table 3. The calculation results show that the value coefficient of effective assets of a provincial power grid in 2018 is the highest. 
Table 3. Calculation results of value engineering

\begin{tabular}{c|c|c|c|c|c}
\hline Grid year & 2014 & 2015 & 2016 & 2017 & 2018 \\
\hline Functional index & 0.62851 & 0.73712 & 0.80860 & 0.88728 & 0.97983 \\
\hline Functional coefficient & 0.15552 & 0.18240 & 0.20009 & 0.21955 & 0.24245 \\
\hline Cost index & 0.16702 & 0.18487 & 0.21089 & 0.21171 & 0.22553 \\
\hline Cost factor & 0.16702 & 0.18487 & 0.21089 & 0.21171 & 0.22553 \\
\hline Value factor & 0.93118 & 0.98666 & 0.94878 & 1.03705 & 1.07502 \\
\hline Sort & 5 & 3 & 4 & 2 & 1 \\
\hline
\end{tabular}

\section{Conclusion}

Value engineering theory has been widely used in all walks of life in China. In this paper, We construct the performance evaluation index system of grid effective assets, adopt the combined weight calculation method of squared sum of dispersion, and the effective asset performance evaluation method of power grid is studied by taking the value coefficient as the evaluation standard of the effective asset performance level. Among them, the use of combined weights realizes the scientific, objective and fair calculation of the weight of the effective assets of the grid, and improves the credibility of the value engineering evaluation results. Finally, the validity and scientificity of the evaluation method are verified by examples.

\section{Acknowledgement}

This work has been supported by the Science and Technology Project of State Grid Jibei Electric Power Company Limited "Research on evaluation method of effective assets input-output of power grid".

\section{References}

1. J.T. Xu, S.P. Chen, X. Yang, VE,The $1+\mathrm{N}$ model promotes the effective asset formation of the rural network project to speed up and increase efficiency, 35, 2(2016)

2. C. Zhang, M.W. Li, CPEM, The Influence of Electric Reform on the Verification and Management of Effective Assets of Power Grid, 4(2017)

3. H.Y. Dong, J. Zhang, Q. Liu, J. Yang, Y.M. Tang, PTAP, Research on Verification Method of Effective Assets of Transmission and Distribution_-Based on Choquet Point Investment Evaluation Model, 4(2016)

4. Z. Ye, W. He, PTAP, Determination Method of Effective Assets of Foreign Transmission and Distribution Network and Its Enlightenment, 4(2017)
5. F. Wu, CUOSAT, Changsha University of Science and Technology, Effective Asset Accounting Method for Transmission and Distribution Based on Utilization Efficiency, 73(2017) 